Letztere war aus der $\mathrm{C}_{16}$-Monoensäure durch oxydativen Abbau entstanden.

Die im Kölbchen befindlichen Kristalle wurden im Waschwasser gelöst und gefriergetrocknet. Rückstand: Abbaudicarbonsäuren: 17,7 mg (11,2 mg). Wegen der kleinen Menge wurden diese lediglich papierchromatographisch untersucht (nach KLENK und TomUSCHAT ${ }^{24}$ ).

Absteigende Chromatographie: (Schleicher \& Schüll 2043 b) Mobile Phase: untere Phase eines Gemisches aus $10 \mathrm{Tln}$. Eisessig, $100 \mathrm{Tln}$. eines 5-proz. Butanol enthaltenden Chloroforms und $100 \mathrm{Tln}$. Wasser, das bei $25-28{ }^{\circ} \mathrm{C} 1$ Stde. äquilibriert wurde. Stabile Phase: obere Phase des beschriebenen Gemisches. Jeweils $50 \gamma$ Fettsäure aufgetragen. Laufzeit $5-6 \mathrm{Stdn} ., T_{.}: 25^{\circ} \mathrm{C}$. Vor der Anfärbung wurde geprüft, ob das Papier völlig frei von Essigsäure war. Nachweis der Dicarbonsäuren: 1 Teil 1-n. KJ; 1 Teil $0,2-n . \mathrm{KJO}_{3} ; 20$ Tle. 3-proz. Stärke; 20 Tle. Wasser. (Lösung kurz vor Gebrauch ansetzen. Falls sie blau gefärbt ist, muß mit $\mathrm{Na}_{2} \mathrm{~S}_{2} \mathrm{O}_{3}$ $(n / 10)$ bis zur Farblosigkeit titriert werden). Das Chromatogramm zeigte nach dem Einsprühen (5 bis 10 Min.) violette Flecken auf weißem Grund.

24 E. KlenK u. H. J. Tomuschat, noch unveröffentlicht.

Abb. 8. Papierchromatogramm der Abbau-Dicarbonsäuren der Fettsäure-Fraktion $\mathrm{C}$ aus Spinat (nach KLenK und TomuSCHAt ${ }^{24}$ ). 1. Abbau-Dicarbonsäuren der Fettsäure-Fraktion, 2 Test: Pimelinsäure, 3 Test: Adipinsäure, 4 Test: Glutarsäure, 5 Test: Bernsteinsäure, 6 Test: Malonsäure.

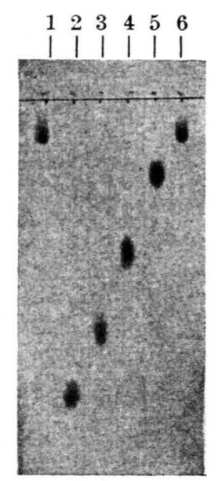

Wie aus Abb. 8 zu ersehen ist, waren als AbbauDicarbonsäuren nur Malonsäure nachweisbar.

Die Abbau-Dicarbonsäuren der entsprechenden Fettsäure-Fraktion aus Löwenmaulblättern ergaben das gleiche Bild.

Die Arbeit wurde mit Unterstützung der De u t $\mathrm{schen}$ Forschungsgemeinschaf turchgeführt. Frl. D. BIELEFELd sei für ihre Mitarbeit gedankt.

\title{
Über die Phosphatkapazität der Gärung und ihr Modell als Ursachen des Crabtree-Effekts der Krebszellen
}

(Mit einer experimentellen Entgegnung auf eine Arbeit von

K. Letnansky und F. Seelich ${ }^{1}$ )

Von Lutz Kiesow

Aus dem Physiologisch-Chemischen Institut der Freien Universität Berlin, Berlin-Dahlem

(Direktor: Prof. Dr. Dr. ERNSt Schütte)

(Z. Naturforschg. 16 b, 567-575 [1961] ; eingegangen am 5. Juni 1961)

\begin{abstract}
Da Glucose und 2-Desoxy-D-glucose in Ascites-Krebszellen gleich große Erniedrigungen der Orthophosphat-Konzentration verursachen, hemmen sie die Atmung dieser Zellen gleich stark. Sie führen beide zu gleich großem C r a b t r e e - Effekt.
\end{abstract}

"The tentative conclusion is that the glycolytic activity exerts a significant chocking effekt on the capacity for respiration of tumour tissue." Mit diesem Satz faßte Crabtree ${ }^{2} 1929$ seine Experimente zusammen, die zu dem Ergebnis führten, das wir heute als $\mathrm{C}$ r a b t r e e - Effekt bezeichnen. Im Gegensatz zur P a s t e u r - Reaktion, die die normalen, die embryonalen und die Krebszellen besitzen - die letzteren zeigen sie sogar, genau so wie die wachsen-

1 K. Letnansky u. F. Seelich, Z. Krebsforsch. 64, 1 [1960].

2 H. G. Crabtree, Biochem. J. 23, 536 [1929].

3 L. Kiesow, Z. Naturforschg. 14 b, 224 [1959]. den Kulturhefezellen ${ }^{3}$, am ausgeprägtesten ${ }^{4}$-, kann man den Crabtree-Effekt nur bei Zellen beobachten, die aerob gären. Man findet ihn also z. B. bei den Ehrlichschen Ascites-Krebszellen und bei Zellen aus der Gewebekultur, aber nicht bei trypsinierten Leber-, Nieren- und Embryonalzellen ${ }^{5}$, wenn man unter physiologischen Bedingungen mißt. Diese Ergebnisse weisen darauf hin, daß man den $\mathrm{Cr}$ a b tree-Effekt nicht als umgekehrten $\mathrm{P}$ a s t e ur-

4 O. Warburg, K. Gawehn u. A.W. Geissler, Z. Naturforschg. $11 \mathrm{~b}, 657$ [1956].

5 L. Kiesow, W. Kattner u. U.Schmitz, Z. Naturforschg. 15 b, 487 [1960]. 
Effekt ansehen darf, denn er tritt erst dann in Erscheinung, wenn die Gärungskapazität der Zellen so groß geworden ist, daß trotz sehr wirksamer Pasteurscher Reaktion Gärung aerob bestehen bleibt.

In den letzten Jahren ist ein Zucker gefunden worden, der bei Krebszellen ${ }^{6}$, Zellen aus der Gewebekultur ${ }^{5}$ und Kulturhefezellen ${ }^{7}$ ebenfalls einen mit Glucose gleich großen Cr a b t r e e - Effekt verursacht, dabei in den Zellen aber lediglich phosphoryliert und weder vergoren noch anderweitig umgesetzt wird. Das ist die 2-Desoxy-D-glucose.

Gegen diese Gleichsetzung des Effektes der DOG mit dem der Glucose protestieren Seelich und Mitarbeiter. Sie bestreiten nicht die Hemmung des Sauerstoffverbrauches durch DOG, erklären aber die Bezeichnung als C rabtre e-Effekt für unzulässig, weil sie nach Zusatz von DOG bei Ascites-Krebszellen eine Erhöhung der Citratkonzentration gefunden haben.

Wenn wir von der experimentellen Frage, ob dieser Befund reproduzierbar ist oder nicht, einmal absehen, so sind von vornherein gegen diese Argumentierung zwei Einwände zu erheben:

Zum einen wird allgemein unter $\mathrm{Crabtree-}$ Effekt die Hemmung der Atmung nach Glucose-Zusatz bezeichnet. Überlegungen, die den Mechanismus dieses Effektes betreffen, spielen für die Kennzeichnung des Effektes als solchen keine Rolle. Insofern wird der bei DOG beobachtete Effekt mit demselben Recht als Crabtree-Effekt bezeichnet, wie der nach Glucose.

Zum andern kann man die Frage stellen, wie sich eine Hemmung der Atmung denn anders auswirken soll als dadurch, daß sich Zwischenprodukte auch des Citronensäure-Zyklus anhäufen. $\mathrm{Ob}$ die Ursache für die Atmungshemmung beim Abbau der Citronensäure oder in der Atmungskette liegt, ist eine Frage, die den Wirkungsmechanismus des Crabtre eEffektes betrifft, aber nicht den Effekt als solchen.

Soweit die theoretische Entgegnung zu dem vorgetragenen Einwand. Die experimentelle Entgegnung wird in dieser Arbeit dargelegt.

Ich habe in den letzten Jahren an verschiedenen Zellen mit der 2-Desoxyglucose experimentiert und dabei gefunden, daß man durch diesen Zucker die Orthophosphorsäure-Konzentration der lebenden Zel-

${ }^{6}$ K. H. Ibsen, E. L. Coe u. R. W. McKee, Biochim. biophysica Acta [Amsterdam] 30, 384 [1958] sowie W. Kattner [1958] Versuche aus der unveröffentlichten Dissertation. len erniedrigen kann ${ }^{8}$, da bei der Phosphorylierung der Desoxyglucose Orthophosphat mit Hilfe des von der Atmung gebildeten ATP im 2-Desoxyglucose-6phosphat fixiert wird.

Die Voraussetzung, Zucker aerob in nennenswertem Maße zu phosphorylieren, besitzen die Krebszellen ${ }^{5}$, die Zellen aus der Zellkultur ${ }^{5}$ und die Kulturhefen ${ }^{7}$. Bei allen diesen Zellen verursacht 2-Desoxyglucose eine Atmungshemmung, die fast genauso groß ist, wie die durch Glucose. An Kulturhefe konnte ich zeigen, daß Orthophosphat-Erniedrigung und Atmungshemmung durch Desoxyglucose parallel gehen und kam zu dem Schluß, daß die Orthophosphat-Erniedrigung in den Zellen die Ursache des Crabtre e-Effektes ist ${ }^{9}$. Das viel günstigere $\mathrm{Ob}$ jekt für diese Versuche, die Ascites-Krebs-Zellen, standen mir damals infolge einer Seuche unseres Mäusestammes nicht zur Verfügung, so daß ich die Experimente erst später nachholen konnte. Die Ergebnisse, die die an Hefe erhaltenen Befunde voll bestätigen, werden in der vorliegenden Arbeit mitgeteilt. Sie erweitern die Hefeexperimente insofern, als gezeigt wird, daß Glucose und Desoxyglucose, zwar auf etwas anderem Wege, zu einer praktisch gleich großen Erniedrigung der Orthophosphat-Konzentration intakter Krebszellen führen, genauso, wie sie auch annähernd gleich große Crabtree-Effekte verursachen.

Die von Letnansky und Seelich ${ }^{1}$ gefundene große Citratanhäufung durch Desoxyglucose habe ich unter keinen Versuchsbedingungen beobachtet.

\section{Phosphatkapazität der Gärung und ihr Modell}

Wir punktieren den Ascites eines E hr li c h schen Mäuse-Ascites-Carcinoms und machen ihn durch Heparin ungerinnbar. Je $4,5 \mathrm{~cm}^{3}$ der unverdünnten oder durch inaktiviertes Ascitesserum verdünnten Zellsuspension werden in 3 kegelförmige Manometriegefäße gefüllt, von denen eines $0,15 \mathrm{~cm}^{3}$ inaktiviertes Serum, das zweite $0,15 \mathrm{~cm}^{3}$ inaktiviertes Serum mit $9,3 \mathrm{mg}$ Glucose und das dritte $0,15 \mathrm{~cm}^{3}$ inaktiviertes Serum mit 9,3 mg Desoxy-D-glucose in den Birnen enthält. In die Gasräume werden 5 Vol.-\% $\mathrm{CO}_{2}$-Luft eingefüllt und die Gefäße bei $38^{\circ} \mathrm{C}$ im Thermostaten wie zur Manometrie geschüttelt.

\footnotetext{
7 L. Kiesow, Z. Naturforschg. 14 b, 492 [1959].

8 L. Kiesow, Z. Naturforschg. 15 b, 293 [1960].

${ }^{9}$ L. Kiesow, Z. Naturforschg. 16 b. 32 [1961].
} 
Nach 20 min kippen wir den Inhalt der Birnen ein und beenden den Versuch nach weiteren $20-30 \mathrm{~min}$ durch Enteiweißen mit 5\% Trichloressigsäure in der Endverdünnung. Analysiert man nach dem Abzentrifugieren der Niederschläge die drei Gefäßinhalte auf Orthophosphat, so findet man z. B. (s. auch im experimentellen Teil) :

\begin{tabular}{|c|c|}
\hline \multicolumn{2}{|c|}{$\begin{array}{c}\text { im Gefäß 1 } \\
(\text { ohne Zucker) } \\
18,8 \mu \text { Mole } \mathrm{PO}_{4}{ }^{3}{ }^{\ominus}\end{array}$} \\
\hline $\begin{array}{c}\sqrt{\downarrow} \\
\text { im Gefäß } 2 \\
\text { (Glucose) }\end{array}$ & $\begin{array}{c}\downarrow \\
\text { im Gefäß } 3 \\
\text { (2-Desoxyglucose) }\end{array}$ \\
\hline $1,8 \mu$ Mole $\mathrm{PO}_{4}{ }^{3 \ominus}$ & $12,3 \mu$ Mole $\mathrm{PO}_{4}{ }^{3 \ominus}$ \\
\hline
\end{tabular}

Wie man sieht, haben die Zucker in den Gefäßen 2 und 3 die Orthophosphat-Konzentration der Zellsuspensionen etwa gleich stark gegenüber Gefäß 1 herabgesetzt. Mißt man die Atmungsgrößen unter den gleichen Bedingungen dieses Experimentes, so findet man unter den Bedingungen der Gefäße 2 und 3 gegenüber Gefäß 1 ebenfalls fast gleich stark gehemmte Atmungen, also gleich große $\mathrm{C} \mathrm{r}$ a b t r e e Effekte (s. experimenteller Teil).

Wir entnehmen diesem Experiment, daß gleich starke Orthophosphat-Erniedrigungen gleich starke Atmungshemmungen verursachen. Ein Ergebnis, das mit den Versuchen an Hefe völlig übereinstimmt ${ }^{9}$ (wie weitgehend die Übereinstimmung ist, zeigen im einzelnen die Versuche im experimentellen Teil dieser Arbeit). In bezug auf die chemischen Ursachen der Phosphat-Erniedrigung unterscheiden sich aber die Zellen der Gefäße 2 und 3. Im Gefäß 2 kommt es zur aeroben Gärung, d. h. es entstehen die phosphorylierten Zwischenstoffe des Embden-Meyer h of - Weges der Gärung in Konzentrationen, die von den Gleichgewichtslagen der einzelnen Teilreaktionen abhängen. Bei dem Aufbau dieser ZwischenstoffKonzentrationen wird das Orthophosphat der Zelle zu einem beträchtlichen Teil in organisch gebundenes Phosphat überführt *.

Im Gefäß 3 aber entsteht nur ein Hexosephosphat, nämlich 2-Desoxyglucose-6-phosphat, das allerdings, und das ist ein Zufall, außer über Hexose-monophosphatase nicht weiter umgesetzt wird. Deshalb häuft es sich stark an, so daß es genau so viel Ortho-

* Vgl. hierzu: E. Kvamme, Acta physiol. scand. 42, 204 [1958] sowie R. Wu u. E. Racker, J. biol. Chemistry 234, 1036 [1959]. phosphat in organischer Bindung fixiert wie die Summe der phosphorylierten Zwischenstoff-Konzentrationen der Gärung ausmacht.

Bezeichnet man diese Summe der phosphorylierten Gärungszwischenstoffe als Phosphatkapazität der Gärung, die, wenn sie sich in einer Zelle aufladen kann, zu einer Orthophosphat-Erniedrigung und damit zu der Atmungshemmung des Crabtree-Effektes führt, dann ist die Phosphorylierung der 2-Desoxyglucose ihr Modell. Sie ist zufälligerweise ein sehr gutes Modell, da sie praktisch zur gleichen Orthophosphat-Erniedrigung in der Zelle führt.

Aus diesem Resultat ergeben sich Konsequenzen, die eine Reihe von Phänomenen nunmehr zwanglos erklären:

Besitzt eine Zelle die Fähigkeit aerob zu gären, wie es von W wurde ${ }^{10}$, so kann sie aerob, wenn ihr Glucose zur Verfügung steht, die Phosphatkapazität der Gärung aufladen. Damit wird ihre Orthophosphat-Konzentration erniedrigt und ihre Atmung gehemmt. Die Atmung wird somit, da sie Phosphat benötigt, von der Gärung abhängig und es entsteht in Anwesenheit von Glucose die kleine Atmung der Krebszellen. Die Voraussetzung für die hohe Gärung und den Aufbau der Phosphatkapazität der Krebszellen ist die schnelle Zuckerphosphorylierung, durch die sich lebende Krebszellen von normalen und embryonalen Zellen unterscheiden ${ }^{5}$ und deshalb wird das Modell, die Desoxyglucose, ebenfalls schnell und stark phosphoryliert. Es ersetzt die Phosphatkapazität, erniedrigt Orthophosphat gleich stark und macht deshalb die Atmung von der isolierten Zuckerphosphorylierung genauso abhängig, wie sie es sonst von der Gärung ist.

Normale Körperzellen und embryonale Zellen, die aerob nicht glykolysieren, haben aerob keine Phosphatkapazität der Gärung. Sie haben auch keine schnelle Zuckerphosphorylierung und deshalb hemmen weder Glucose noch 2-Desoxyglucose die Atmung dieser Zellen ${ }^{5}$. Entstehen aber beim in vitroWachstum, z. B. embryonaler Zellen, Zellen mit aerobem Gärungsstoffwechsel, so entsteht damit auch die Fähigkeit zur Auffüllung der Phosphatkapazität, deshalb führt Glucose bei diesen Zellen zum $\mathrm{C} \mathrm{r} \mathrm{a} \mathrm{b} \mathrm{-}$ t r e e - Effekt, und da auch hier die schnelle Zuckerphosphorylierung entstanden ist ${ }^{5}$, wirkt das Modell

10 O. W 309 [1924]. 
der Phosphatkapazität, die Desoxyglucose, wie die Glucose.

Fassen wir also zusammen: Besitzt oder erwirbt eine Zelle die Fähigkeit zur aeroben Gärung, so wird die Atmung dieser Zelle zu einem Trabanten dieser Gärung, wobei das Orthophosphat der Mittler ist. Ist Glucose zugegen, so sinkt die Atmung infolge einer Orthophosphat-Erniedrigung durch die Phosphatkapazität der Gärung ab, genauso wie sie durch die Orthophosphat-Erniedrigung abnimmt, wenn Desoxyglucose das Modell dieser Phosphatkapazität ist. Da sowohl der physiologische Mechanismus als auch sein Modell die hohe Zuckerphosphorylierung zur Voraussetzung haben, kommt ihr im Zusammenhang mit dem Gärungsstoffwechsel der Tumoren und seiner Entstehung eine erhebliche Bedeutung zu, denn sie erklärt die hohe Gärung der Tumoren, und, wie diese Arbeit zeigt, den C r a b tr e e - Effekt und damit die kleine Atmung der Krebszellen. Ich habe mich deshalb mit ihren fermentchemischen und chemischen Ursachen beschäftigt, worüber ich in der nachfolgenden Arbeit mit S. DöGE berichte.

\section{Die durch Desoxyglucose hervorgerufene Citratanhäufung von Letnansky und Seelich}

Nach Letnansky und SeELich ${ }^{1}$ soll 2-Desoxyglucose die Reaktionen des Citronensäurecyclus der Ascites-Krebszellen derart beeinflussen, daß sie ein Absinken der Citronensäure bei Inkubation in $\mathrm{R}$ i n g e r - Lösung und in R in g e r - Lösung-Glucose verhindert. Sie soll ferner bei Anwesenheit von Pyruvat nicht nur das Absinken des Citrates verhindern, sondern im Gegenteil einen Citratanstau bewirken, der in dem mitgeteilten Versuch das 5,2-fache des Wertes ohne Desoxyglucose erreicht. Da mir dieser Citratanstau als Bieweis gegen die von mir vertretene Ansicht vorgehalten wurde, wollte ich mit ihm experimentieren, um ihn verstehen zu lernen.

Wie aus dem Versuchsteil hervorgeht, ist es mir weder bei Kulturhefe, noch bei Ascites-Krebszellen gelungen, diesen großen Citrateffekt der Desoxyglucose zu sehen, obwohl ich mich sehr darum bemüht habe. Lediglich bei Ascites-Krebszellen in Ascites-Serum konnte ich eine geringe Erhöhung der Citratkonzentration beobachten, und zwar sowohl mit Glucose als auch mit Desoxyglucose (s. Protokoll 4). So war im Mittel von 6 Versuchen die Citratkonzentration pro Gefäß:
1. ohne Glucose: $\quad 0,83 \mu$ Mole Citrat ,

2. mit Glucose: $\quad 0,88 \mu$ Mole Citrat ,

3. mit 2-Desoxyglucose: $0,94 \mu$ Mole Citrat .

Mit Desoxyglucose war also Citrat gegenüber zuckerfreiem Medium auf das 1,13-fache erhöht und mit Glucose auf das 1,06-fache. Aber gerade diese Versuchsreihe beweist auf einem unabhängigen Wege, daß Orthophosphat die Ursache der Atmungshemmung durch Glucose und Desoxyglucose ist. Vergleicht man nämlich die Mittelwerte der Orthophosphat-Konzentrationen im Gefäß mit Glucose und in dem mit 2-Desoxyglucose (wie das in Protokoll 4 möglich ist), so findet man:

1. mit Glucose: $8,1 \mu$ Mole Phosphat,

2. mit Desoxyglucose: $7,6 \mu$ Mole Phosphat .

und damit hat man den Schlüssel zum Verständnis der kleinen Unterschiede bei den geringen Citraterhöhungen mit Glucose und Desoxyglucose in der Hand: Die Erniedrigung der Orthophosphat-Konzentration durch die Phosphatkapazität der Gärung, also durch Glucose, ist etwas geringer als die Erniedrigung der Orthophosphat-Konzentration durch 2-Desoxyglucose. Die Folge davon ist eine etwas geringere Atmungshemmung mit Glucose als mit Desoxyglucose. Die Atmungshemmung führt aber in jedem Fall zu einem geringen Anstieg der Citratkonzentration, der also im Versuch mit Glucose auch etwas kleiner ist als im Versuch mit Desoxyglucose.

Fast wäre also das Módell der Phosphatkapazität der Gärung, die Phosphorylierung der Desoxyglucose, ein ideales Modell. Vielleicht erklärt dieses Ergebnis auch die experimentellen Unterschiede im Wiener und im Berliner Laboratorium. Wenn nämlich die Phosphat-Erniedrigung durch Desoxyglucose bei den in Wien verwendeten Ascites-Krebszellen größer ist als bei den von uns benutzten Zellen, so muß man bei dem Versuch in Wien eine höhere Citratkonzentration finden als bei dem Versuch in Berlin. Auch in diesem Zusammenhang möchte ich auf die Ergebnisse der nachfolgenden Arbeit mit S. DögE verweisen.

\section{Experimenteller Teil}

B estimmung der Citronensäure

Die Citronensäure bestimmten wir nach NATkLSON und Mitarbb. ${ }^{11}$. Dazu wird der durch 5\% Trichloressigsäure in der Endverdünnung enteiweißte Versuchsansatz

11 S. Natelson u. Mitarbb., J. biol. Chemistry 170, 597 [1947]. 
zentrifugiert, der Überstand mit $0,3 \mathrm{~cm}^{3}$ 50-proz. $\mathrm{H}_{2} \mathrm{SO}_{4}[\mathrm{~V} / \mathrm{V}]$ versetzt und in einem Meßzylinder mit eingeschliffenem Glasstopfen genau 1 min auf siedendem Wasserbad erwärmt. Nach dem Abkühlen werden weitere $0,3 \mathrm{~cm}^{3} 50$-proz. $\mathrm{H}_{2} \mathrm{SO}_{4}[\mathrm{~V} / \mathrm{V}]$ sowie $0,2 \mathrm{~cm}^{3}$ 1-n. wäßriges $\mathrm{KBr}$ zugefügt und mit Wasser auf $5 \mathrm{~cm}^{3}$ aufgefüllt. Bei Zimmertemperatur wird 1-n. $\mathrm{KMnO}_{4}$ unter Schütteln in kleinen Tropfen langsam solange zugesetzt, bis die Permanganatfarbe eben bestehen bleibt. $10 \mathrm{~min}$ bleiben die Proben bei Zimmertemperatur, dann werden sie 5 min im Eisbad gekühlt. Im Eisbad tropft man nun 3-proz. $\mathrm{H}_{2} \mathrm{O}_{2}$ sehr langsam solange ein, bis völlige Entfärbung stattgefunden hat. Um sicher zu gehen, daß kein überschüssiges $\mathrm{H}_{2} \mathrm{O}_{2}$ mehr vorhanden ist, wird langsam $0,1-n . \mathrm{KMnO}_{4}$ eingetropft, bis die Permanganatfarbe gerade noch verschwindet. Nun wird mit Wasser auf $10 \mathrm{~cm}^{3}$ aufgefüllt und danach $7 \mathrm{~cm}^{3}$ n-Heptan zugegeben. Die Proben bleiben weitere $5 \mathrm{~min}$ im Eisbad. Dann werden die Proben genau $2 \cdot 30 \mathrm{sec}$ mit 15 sec Pause kräftig geschüttelt und verbleiben bis zur völligen Phasentrennung weiter im Eisbad. Die wäßrige untere Phase wird jetzt abgesaugt und durch $5 \mathrm{~cm}^{3}$ Wasser ersetzt. Nach 10 min Kühlen im Eisbad wird erneut $2 \cdot 30 \mathrm{sec}$ mit $15 \mathrm{sec}$ Pause kräftig geschüttelt. Nach erfolgter Phasentrennung werden $5 \mathrm{~cm}^{3}$ der oberen (Heptan) Schicht zu $5 \mathrm{~cm}^{3}$ Thioharnstoff-BoraxLösung (4 g Thioharnstoff und $2 \mathrm{~g}$ Borax in $100 \mathrm{~cm}^{3}$ $\mathrm{H}_{2} \mathrm{O}$ ) in große Schliffreagenzgläser pipettiert, $10 \mathrm{~min}$ in ein Eisbad gebracht und dann $2 \cdot 30 \mathrm{sec}$ mit $15 \mathrm{sec}$ Pause geschüttelt. Nach weiteren $20 \mathrm{~min}$ im Eisbad wird die Lichtschwächung der wäßrigen unteren Phase bei $\lambda=436 \mathrm{~m} \mu$ und $d=1 \mathrm{~cm}$ gemessen. Eine eventuelle Trübung wird durch die Messung bei $\lambda=578 \mathrm{~m} \mu$ eliminiert.

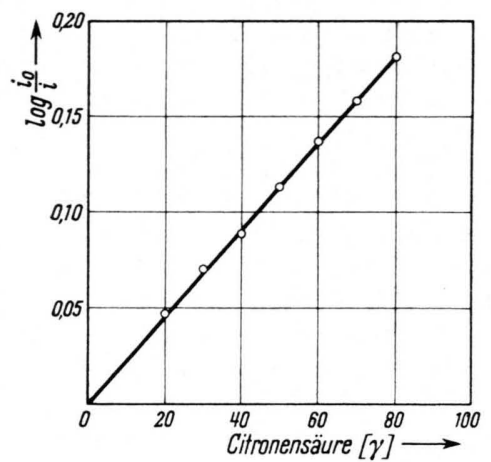

Abb. 1. Die Beziehung zwischen dem Logarithmus der Lichtschwächung bei $\lambda=436 \mathrm{~m} \mu$ und $d=1 \mathrm{~cm}$ und der Citronensäure-Konzentration.

Diese chemische Bestimmung der Citronensäure ist zwar recht umständlich, ergibt aber, wie die Eichkurve in Abb. 1 zeigt, für Citratbestimmungen ungewöhnlich genaue Werte.

12 O. Warburg u. G. Krippahl, Z. Naturforschg. 13 b, 434 [1958].
Bestimmung der Orthophosphorsäure

Um die Orthophosphorsäure in den Zellsuspensionen zu bestimmen, wird sie mit eiskalter Trichloressigsäure enteiweißt und extrahiert. Nachdem die Proben 30 min im Eisbad gehalten wurden, zentrifugieren wir bei $0{ }^{\circ} \mathrm{C}$ und bestimmen Orthophosphat in den Überständen nach der Phosphorbestimmung, die in den klinisch-chemischen Untersuchungsmethoden zum Photometer Eppendorf beschrieben ist. Die Lichtschwächung wird bei $\lambda=578 \mathrm{~m} \mu$ und $d=2 \mathrm{~cm}$ gemessen. Die Werte erhalten wir in $\gamma \mathrm{P}$ mit Hilfe einer Eichkurve (Abb. 2).

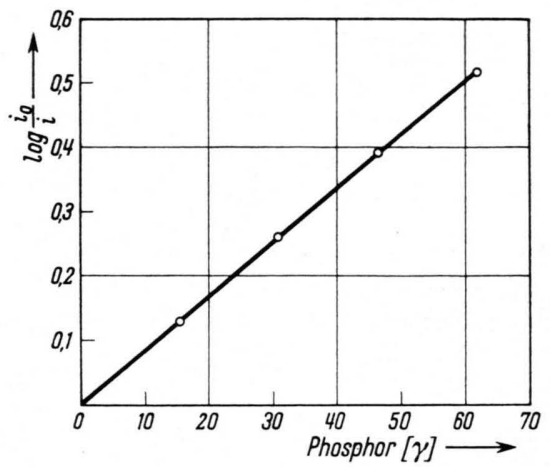

Abb. 2. Die Beziehung zwischen dem Logarithmus der Lichtschwächung bei $\lambda=578 \mathrm{~m} \mu$ und $d=2 \mathrm{~cm}$ und der Phosphatkonzentration.

Ma nometrie

Die manometrischen Messungen an Hefezellen erfolgten bei $20^{\circ} \mathrm{C}$ in Wannengefäßen ${ }^{12}$ mit Kalilauge in der Wanne. Die Atmungsmessungen an Ascites-Krebszellen wurden in kegelförmigen Anhängergefäßen ${ }^{13}$ durchgeführt, wobei Bicarbonat-Carbonatgemische in den Anhängern den $\mathrm{CO}_{2}$-Druck im Gasraum konstant hielten. Die Thermostatentemperatur betrug bei allen Versuchen $38{ }^{\circ} \mathrm{C}$. Mißt man die Zellatmung mit Hilfe der Bicarbonat-Carbonatgemische, so muß man sich zunächst davon überzeugen, wie groß die $\mathrm{CO}_{2}$-Retention des $\mathrm{Ge}$ misches bei der jeweiligen Versuchstemperatur ist. Wenn sie hinreichend groß ist (im Idealfall $\infty$ ), sind Korrekturen für gebildetes $\mathrm{CO}_{2}$ oder Milchsäure überflüssig. Wenn sie aber klein ist, so wird gebildetes $\mathrm{CO}_{2}$ unvollständig retiniert. Experimentiert man in einem solchen Fall mit Zellen, die ausschließlich atmen, so kann man die Atmungskohlensäure folgendermaßen berücksichtigen: In einem Anhängergefäß sind im Hauptraum $3 \mathrm{~cm}^{3}$ Zellsuspension in Serum, im Anhänger $3 \mathrm{~cm}^{3}$ Bicarbonat-Carbonat-Gemisch mit $2 \mathrm{mg}$ Kohlensäureanhydratase. Die Gefäßkonstanten betrugen:

$$
k_{\mathrm{CO}_{2}}=3,417 \mathrm{~mm}^{2}, \quad k_{\mathrm{O}_{2}}=3,107 \mathrm{~mm}^{2} .
$$

Die $\mathrm{CO}_{2}$-Retention für $3 \mathrm{~cm}^{3}$ Serum ist :

$$
R_{\mathrm{CO}_{2}}^{\mathrm{Serum}}=0,311 \mathrm{~mm}^{3} \mathrm{CO}_{2} / \mathrm{mm} \text { Brodie }
$$

13 O. Warburg u. G. KRIPPAhl, Z. Naturforschg. 15 b, 364 [1960]. 
und die $\mathrm{CO}_{2}$-Retention des Gemisches:

$$
R_{\mathrm{CO}_{2}}^{\mathrm{Gemisch}}=58,850 \mathrm{~mm}^{3} \mathrm{CO}_{2} / \mathrm{mm} \text { Brodie } .
$$

Die Gefäßkonstante für $\mathrm{CO}_{2}$ unter Berücksichtigung der Gesamtretention beträgt:

$$
\begin{aligned}
& k_{\mathrm{CO}_{2}}^{R}=k_{\mathrm{CO}_{2}}+R_{\mathrm{CO}_{2}}^{\mathrm{Serum}}+R_{\mathrm{CO}_{2}}^{\mathrm{Gemisch}} \\
& k_{\mathrm{CO}_{2}}^{R}=3,417+0,311+58,850=62,578 \mathrm{~mm}^{2}
\end{aligned}
$$

und weiter ist :

$$
x_{\mathrm{O}_{2}}=h \cdot \frac{k_{\mathrm{CO}_{2}}^{R}}{k_{\mathrm{CO}_{2}}^{R}+\gamma \cdot k_{\mathrm{O}_{2}}} \cdot k_{\mathrm{O}_{2}}
$$

oder für unser Gefäß :

$$
x_{\mathrm{O}_{2}}=h \cdot \frac{62,578}{62,578+\gamma \cdot 3,107} \cdot k_{\mathrm{O}_{2}} \cdot
$$

Nimmt man an, daß $\gamma$ der Zellatmung zwischen $-1,0$ und $-0,5$ schwankt, so bedeutet das für den Korrekturfaktor eine mögliche Schwankung zwischen:

$$
1,052 \text { und } 1,025 \text {. }
$$

Rechnet man also mit $\gamma=-0,75$, so ist :

$$
x_{\mathrm{O}_{2}}=h \cdot 1,038 \cdot k_{\mathrm{O}_{2}} \text {. }
$$

Hat man in einem Versuch z. B. Druckänderungen von $-50 \mathrm{~mm}$ Brodie, so kann durch die Unsicherheit von $\gamma$ der Fehler nur:

$$
x_{\mathrm{O}_{2}}=(-161,2 \pm 2,1) \mathrm{mm}^{3}
$$

ausmachen, also \pm 1,2 Prozent.

Wenn die Zellen im Hauptraum des Gefäßes nicht nur atmen, sondern auch aerob glykolysieren, so bestimmen wir die Milchsäure-Retention $\left(R_{\mathrm{M}}^{\text {Serum }}\right)$ von $3 \mathrm{~cm}^{3}$ Serum und mit Hilfe des optischen Testes die von den Zellen während der Versuchszeit gebildete Milchsäure. Dazu wird der Milchsäuregehalt in einem äquivalenten Teil der Zellsuspension mit Hilfe des Testbesteckes zur Milchsäurebestimmung von Boehringer zur Zeit $t=0$ und $t=\mathrm{x}$ ermittelt, wodurch man weiß, wieviele $\mu$ Mole Milchsäure in dem Gefäß während des Versuches entstanden sind. Damit wird also die aerobe Glykolyse bestimmt. Man kann die $\mu$ Mole Milchsäure mit 22,4 multiplizieren und erhält so $x_{\mathrm{M}}$, das man folgendermaßen in die durch die Milchsäurebildung im Gefäß verursachte Druckänderung umrechnen kann. Sind $x_{M}$ Milchsäure gebildet worden, so ist :

$$
h_{\mathrm{M}}=\frac{x_{\mathrm{M}}}{\left(k_{\mathrm{CO}_{2}}+R_{\mathrm{M}}^{\mathrm{Serum}}+R_{\mathrm{CO}_{2}}^{\mathrm{Gemisch}}\right)},
$$

wobei $R_{\mathrm{CO}}^{\mathrm{Gemisch}}$ die $\mathrm{CO}_{2}$-Retention des $3 \mathrm{~cm}^{3}$ Bicarbonat-Carbonat-Gemisches und $k_{\mathrm{CO}_{2}}$ die Gefäßkonstante des Gefäßes für Kohlensäure bei der Versuchstemperatur sind. $h_{\mathrm{II}}$ ist somit die durch die Milchsäurebildung verursachte Druckänderung, die manometrisch in Erscheinung tritt. Geht $R_{\mathrm{CO}_{2}}^{\mathrm{Gemisch}} \rightarrow \infty$, so geht $h_{\mathrm{MI}} \rightarrow 0$.
Um so höher also die $\mathrm{CO}_{2}$-Retention des Anhängergemisches ist, um so geringer ist der Fehler. Ist z. B. in einem Versuch:

$$
\begin{aligned}
x_{\mathrm{MI}} & =175 \mathrm{~mm}^{3} \text { Milchsäure, } R_{\mathrm{M}}^{\text {Serum }}=0,745 \mathrm{~mm}^{2}, \\
R_{\mathrm{CO}_{2}}^{\mathrm{Gemisch}} & =58,85 \mathrm{~mm}^{2} \text { und } k_{\mathrm{CO}_{2}}=3,417 \mathrm{~mm}^{2},
\end{aligned}
$$

so ist

$$
h_{\mathrm{M}}=\frac{175 \mathrm{~mm}^{3}}{(3,417+0,745+58,85) \mathrm{mm}^{2}}=2,8 \mathrm{~mm} .
$$

War in der gleichen Versuchszeit der $\mathrm{O}_{2}$-Verbrauch z. B. $x_{\mathrm{O}_{2}}=30 \mathrm{~mm}^{3} \mathrm{O}_{2}$, was einer Druckänderung von

$$
h=\frac{x_{\mathrm{O}_{2}}}{K_{\mathrm{O}_{2}}}=\frac{30}{3,225}=9,3 \mathrm{~mm}
$$

entspricht, so sieht man, daß bei hoher aerober Glykolyse und kleiner Atmung diese Glykolyse-Korrektur unbedingt erforderlich ist.

Die $\mathrm{CO}_{2}$-Retention und die Milchsäure-Retention für $3 \mathrm{~cm}^{3}$ Serum bestimmt man hintereinander in einem kegelförmigen Manometriegefäß mit einer Birne und einer zur zweiten Birne durchgeschmolzenen Wanne. Die $\mathrm{CO}_{2}$-Retention des jeweiligen Bicarbonat-CarbonatGemisches wird in den Anhängergefäßen bestimmt, wobei der Hauptraum überschüssige Säure und die Birne abgemessenes Bicarbonat enthalten. Man kann die Retentionsbestimmungen aber auch dadurch vereinfachen, daß man in den Anhängergefäßen $\left(R_{\mathrm{M}}^{\mathrm{Serum}}+R_{\mathrm{CO}_{2}}^{\mathrm{Gemisch}}\right)$ bestimmt, indem man abgemessene Säure aus der Birne in $3 \mathrm{~cm}^{3}$ Serum in den Hauptraum einkippt. Analog dazu bestimmt man $\left(R_{\mathrm{CO}_{2}}^{\mathrm{Serum}}+R_{\mathrm{CO}_{2}}^{\mathrm{Gemisch}}\right)$ in einem Anhängergefäß mit zur Birne durchgeschmolzener Wanne bzw. mit siamesischer Birne. Die Gefäße enthalten hierbei das im Versuch benötigte Bicarbonat-Carbonat-Gemisch in den Anhängern.

$$
\text { Versuchsobjekte }
$$

Die Kulturhefe war Germaniahefe, Stamm A, der Norddeutschen Hefeindustrie, Hamburg. Sie wurde vor dem Versuch 3-mal mit dest. Wasser auf der Zentrifuge gewaschen. Den Impftumor des Ehrlichschen MäuseAscites-Krebses erhielt ich von Herrn Prof. Отто $W_{\text {AR- }}$ BURG, wofür ich auch an dieser Stelle danken möchte. Der Ascites wurde am 6.-8. Tag nach der Inokulation punktiert und mit Heparin ungerinnbar gemacht, wenn die Ascites-Krebszellen verwendet werden sollten.

$$
\text { Protokoll } 1
$$

Die Oxydation von Pyruvat durch Kulturhefezellen kann man durch 2-Desoxy-D-glucose hemmen

Manometrische Bedingungen:

Kegelförmige Manometriegefäße mit Wanne und einer Birne. $\quad \mathrm{v} \approx 19 \mathrm{~cm}^{3}, \quad t=20{ }^{\circ} \mathrm{C}, \quad v=220 / \mathrm{min}$, $\varepsilon=10 \mathrm{~mm}$, Gasphase: Luft. 
Gefäß Nr. :

25

26

$k_{\mathrm{O}_{2}}$

Wanne:

$1,531 \mathrm{~mm}^{2}$

Birne:

$0,3 \mathrm{~cm}^{3} 20$-proz. $\mathrm{KOH}$

$0,1 \mathrm{~cm}^{3} \mathrm{H}_{2} \mathrm{O}$ mit

6,2 mg 2-Desoxyglucose

Hauptraum: $\quad 3 \mathrm{~cm}^{3}$ Zellsuspension

$$
=24 \mathrm{~mm}^{3} \text { Hefezellen in }
$$$$
m / 20-\mathrm{KH}_{2} \mathrm{PO}_{4}
$$

$0,1 \mathrm{~cm}^{3} \mathrm{H}_{2} \mathrm{O}$ mit

$6,2 \mathrm{mg}$ Na-Pyruvat
$1,520 \mathrm{~mm}^{2}$

$0,1 \mathrm{~cm}^{3} \mathrm{H}_{2} \mathrm{O}$

$\rightarrow$

$\rightarrow$

Beginn der Ablesungen 20 min nach dem Schließen der Hähne

$$
\begin{aligned}
& \Delta t[\min ] \\
& \Delta h[\mathrm{~mm}] \\
& \left.10-21,0) x_{0_{2}}=\quad-21,0\right) x_{0_{2}}= \\
& \left.10-20,0\} 62,8 \mathrm{~mm}^{3} \mathrm{O}_{2}-20,5\right\} 63,1 \mathrm{~mm}^{3} \mathrm{O}_{2} \\
& \downarrow \text { Birnen eingekippt } \downarrow \\
& 10-19,5 \quad-21,0 \\
& 10-13,0 \quad-21,0 \\
& 10-7,5 \quad-21,5 \\
& 10-7,0) \quad-21,5 \\
& \left.10-7,0\} x_{\mathrm{O}_{2}}=\quad-20,5\right\} x_{\mathrm{O}_{2}}= \\
& 10-6,5 \int_{31,4 \mathrm{~mm}^{3} \mathrm{O}_{2}}-21,0 \mathrm{Im}^{3} \mathrm{O}_{2}
\end{aligned}
$$

Atmungshemmung: $66,7 \%$

0

$\left[\frac{A_{0}-A}{A_{0}} \cdot 100\right]$

Ergebnis: 2-Desoxyglucose hemmt die Pyruvatoxydation durch Hefe (genauso stark wie die Alkoholoxydation).

\section{Protokoll 2}

Bei der Alkoholoxydation durch Kulturhefe führten weder 2-Desoxyglucose noch Glucose zu einem

$$
\text { Citrat-Anstau }
$$

Temperatur: $20^{\circ} \mathrm{C}$, Gasphase: Luft

Gefäß Nr.:

$$
1
$$

Hauptraum:

$90 \mathrm{~mm}^{3} \mathrm{Hefe}-$

zellen in

$3 \mathrm{~cm}^{3} \mathrm{~m} / 20$ -

$\mathrm{KH}_{2} \mathrm{PO}_{4}$ mit

1\% Äthanol

Birne:

$\begin{array}{ll}0,1 \mathrm{~cm}^{3} \mathrm{H}_{2} \mathrm{O} & 0,1 \mathrm{~cm}^{3} \mathrm{H}_{2} \mathrm{O} \quad 0,1 \mathrm{~cm}^{3} \mathrm{H}_{2} \mathrm{O} \\ \text { mit } 6,2 \mathrm{mg} & \text { mit } 6,2 \mathrm{mg} \\ \text { Glucose } & \begin{array}{l}\text { Desoxy- } \\ \text { glucose }\end{array}\end{array}$

Nach 30 min Schütteln werden die Birnen eingekippt

Nach weiteren 50 min werden aus jedem Gefäß je $2 \mathrm{~cm}^{3}$ zu $1 \mathrm{~cm}^{3}$ 15-proz. Trichloressigsäure pipettiert und nach $30 \mathrm{~min}$ zentrifugiert. Je $2,5 \mathrm{~cm}^{3}$ der Überstände werden auf Citrat analysiert.

$\log \frac{i_{0}}{i}\left[\begin{array}{l}\lambda=436 \mathrm{~m} \mu \\ \mathrm{d}=1 \mathrm{~cm}\end{array}\right]$ 0,123

Citronensäure pro Gefäß

$$
101 \gamma \quad 106 \gamma
$$$$
103 \gamma
$$

Die Mittelwerte aus drei weiteren Versuchen (ohne Rücksicht auf das variierende Zellvolumen)

Citronensäure pro Gefäß: $\quad 103 \gamma \quad 102 \gamma \quad 102 \gamma$

Ergebnis: Bei Alkoholoxydation durch Hefe werden die Citratgehalte der Zellen durch Zusatz von Glucose und 2-Desoxyglucose nicht verändert.

\section{Protokoll 3}

Bei der Pyruvatoxydation durch Kulturhefe ändern weder Glucose noch 2-Desoxyglucose die Citratkonzentration

Der Versuch ist wie in Protokoll 2 angeordnet. Nur sind die Hefezellen abweichend zu Protokoll 2 in $m / 20$ $\mathrm{KH}_{2} \mathrm{PO}_{4}$ mit $200 \mathrm{mg}-\%$ Na-Pyruvat suspendiert.

Gefäß Nr.

$\begin{array}{ccc}1 & 2 & 3 \\ \text { (Glucose) } & \begin{array}{c}\text { (2-Desoxy- } \\ \text { glucose) }\end{array} & \text { Zucker) }\end{array}$

arithmetisches Mittel aus 3 Versuchen ohne Rücksicht auf das variierte Zellvolumen

$\begin{array}{llll}\gamma \text { Citronen- } & 54 \gamma & 53 \gamma & 55 \gamma \\ \text { säure pro } & & \\ \text { Gefäß } & & \end{array}$

Ergebnis: Der Citratgehalt der Zellen zeigt unter den Versuchsbedingungen keine signifikanten Unterschiede.

\section{Protokoll 4}

Der Gehalt an Orthophosphor- und Citronensäure von Ehrlich-Ascites-Krebszellen in Ascites-Serum ohne Zucker, mit $200 \mathrm{mg}-\%$ Glucose und $200 \mathrm{mg}-\%$ Desoxyglucose

Temperatur: $38{ }^{\circ} \mathrm{C}$, Gasphase: 5 Vol. $\% \mathrm{CO}_{2}$-Luft, $\nu=220 / \mathrm{min}, \varepsilon=10 \mathrm{~mm}$.

Gefäß Nr. :

32

33

34

Hauptraum: $\quad 4,5 \mathrm{~cm}^{3}$

Ascites-Zell-

suspension in

Ascites-

Serum

Birne:

$0,15 \mathrm{~cm}^{3}$

Ascites-

$0,15 \mathrm{~cm}^{3} \quad 0,15 \mathrm{~cm}^{3}$

Serum mit

9,3 mg

Ascites-

Ascites-

Glucose

Serum mit Serum

$9,3 \mathrm{mg}$

2-Desoxy-

glucose

20 min wird nach dem Schließen der Hähne geschüttelt, dann wird der Inhalt der Birnen eingekippt und nach weiteren $20-30 \mathrm{~min}$ (je nach Zelldichte) der Versuch dadurch beendet, daß je $4 \mathrm{~cm}^{3}$ der Zellsuspension zu $2 \mathrm{~cm}^{3}$ eiskalter 15-proz. Trichloressigsäure pipettiert werden. Nach $30 \mathrm{~min}$ im Eisbad wird bei $0{ }^{\circ} \mathrm{C}$ abzentri- 


\begin{tabular}{|c|c|c|c|c|c|c|c|}
\hline \multirow[b]{2}{*}{ Nr. } & \multirow{2}{*}{$\begin{array}{c}\text { Ascites-Zellen } \\
\qquad\left[\mathrm{mm}^{3}\right]\end{array}$} & \multicolumn{2}{|c|}{ mit Glucose } & \multicolumn{2}{|c|}{ mit Desoxyglucose } & \multicolumn{2}{|c|}{ ohne Zucker } \\
\hline & & $\begin{array}{l}\text { Citrat } \\
{[\mu \mathrm{M}]}\end{array}$ & $\begin{array}{c}\text { Orthophosphat } \\
{[\mu \mathrm{M}]}\end{array}$ & $\begin{array}{l}\text { Citrat } \\
{[\mu \mathrm{M}]}\end{array}$ & $\begin{array}{c}\text { Orthophosphat } \\
{[\mu \mathrm{M}]}\end{array}$ & $\begin{array}{l}\text { Citrat } \\
{[\mu \mathrm{M}]}\end{array}$ & $\begin{array}{c}\text { Orthophosphat } \\
{[\mu \mathrm{M}]}\end{array}$ \\
\hline 1 & 240 & 0,73 & 7,1 & 0,79 & 3,4 & 0,70 & 11,1 \\
\hline 2 & 765 & 1,04 & 4,2 & 1,11 & 6,3 & 0,90 & 19,5 \\
\hline 3 & 450 & 0,86 & 11,8 & 1,02 & 12,3 & 0,88 & 18,8 \\
\hline 4 & 555 & 0,93 & 7,8 & 0,99 & 6,4 & 0,87 & 14,5 \\
\hline 5 & 440 & 0,91 & 8,3 & 0,95 & 7,5 & 0,84 & 14,4 \\
\hline 6 & 366 & 0,78 & 9,6 & 0,78 & 9,5 & 0,77 & 12,9 \\
\hline \multicolumn{2}{|c|}{ im Mittel: } & 0,88 & 8,1 & 0,94 & 7,6 & 0,83 & 15,2 \\
\hline
\end{tabular}

Tab. 1. Citronen- und Orthophosphorsäure-Gehalt von Ascites-Krebszellen beim C r a b t r e e - Effekt mit Glucose und 2-Desoxyglucose. Die 6 Versuche dieser Tabelle sind gemäß dem Protokoll 4 angeordnet.

fugiert und je $2,5 \mathrm{~cm}^{3}$ Überstand auf Citronensäure und je $0,5 \mathrm{~cm}^{3}$ Überstand auf Orthophosphorsäure analysiert. Da dies der Grundversuch ist, sind die Ergebnisse vgn 6 Versuchen in Tab. 1 zusammengestellt. Alle Werte der Tab. 1 sind auf das Gefäß bezogen.

Ergebnis: Glucose und 2-Desoxyglucose verursachen annähernd gleich starke Orthophosphat-Erniedrigungen. Diese Orthophosphat-Verminderung erfolgt auch in Anwesenheit von extracellulärem Phosphat.

Dieser Grundversuch wurde außerdem mit 0,9-proz. NaCl-Lösung und R inger-Phosphatlösung als Medium durchgeführt, das in beiden Fällen $200 \mathrm{mg}-\%$ Na-Pyruvat enthielt. Die Phosphatkonzentrationen verhielten sich genauso wie im Grundversuch dieses Protokolls. (Mit Ring e r-Phosphat als Medium wurde Phosphat nicht bestimmt.) Citrat war meist überhaupt nicht verändert oder es zeigte die Veränderungen wie im Grundversuch, dann allerdings so gering, daß sie sich innerhalb der analytischen Fehlergrenze bewegten. Ich verzichte deshalb auf die Wiedergabe dieser Protokolle. Sie stehen dem Interessierten jederzeit zur Verfügung.

\section{Protokoll 5}

Steigende 2-Desoxyglucose-Konzentrationen verursachen steigende Orthophosphat-Erniedrigungen und steigende Atmungshemmungen bei Ascites-Krebszellen

Manometrische Bedingungen: $t=38{ }^{\circ} \mathrm{C}, v=220 / \mathrm{min}$, $\varepsilon=10 \mathrm{~mm}$, Gasraum: Luft. Die Zellen wurden vor dem Versuch 2-mal in physiologischer NaCl-Lösung gewaschen.

\section{Gefäß Nr.:}

$$
28
$$$$
29
$$

$k_{\mathrm{O}_{2}}$ :
$3,098 \mathrm{~mm}^{2}$
Hauptraum:
$315 \mathrm{~mm}^{3}$
Asciteszellen
in $3 \mathrm{~cm}^{3}$
$0,9 \mathrm{NaCl}$.
Lösung

$$
3,154 \mathrm{~mm}^{2}
$$$$
3,285 \mathrm{~mm}^{2}
$$$$
3,370 \mathrm{~mm}^{2}
$$

Birne:

$0,1 \mathrm{~cm}^{3}$

0,9 -proz.

$\mathrm{NaCl}$ mit

$1,0 \mathrm{mg}$

2-Desoxy-

glucose

Anhänger :

$3 \mathrm{~cm}^{3} \mathrm{~m} / 5$ -

$\mathrm{NaHCO}_{3}$

$-\mathrm{Na}_{2} \mathrm{CO}_{3}$

(15/85 Vol.)

$+2 \mathrm{mg}$

„Cartase"

\begin{tabular}{lll}
\multicolumn{1}{c}{$\rightarrow$} & $\vec{c}$ & $\rightarrow$ \\
$\begin{array}{l}\text { mit } 0,75 \mathrm{mg} \\
\text { glucose }\end{array}$ & mit $0,5 \mathrm{mg}$ & ohne \\
2-Desoxy- & glucose & 2-Desoxy- \\
& &
\end{tabular}

Da die Retention des $\mathrm{NaHCO}_{3}-\mathrm{Na}_{2} \mathrm{CO}_{3}$-Gemisches sehr groß ist, ist in diesem Versuch $k_{\mathrm{O}_{2}}=K_{\mathrm{O}_{2}}$.

15 min nach dem Schließen der Hähne beginnt die Ablesung.

$\begin{array}{ccccc}\text { Gef. Nr. } & 28 & 29 & 30 & 31 \\ \Delta t[\mathrm{~min}] & \Delta h[\mathrm{~mm}] & \Delta h[\mathrm{~mm}] & \Delta h[\mathrm{~mm}] & \Delta h[\mathrm{~mm}] \\ 10 & -29,5 & -29,5 & -28,5 & -27,5 \\ 10 & -32,0 & -32,0 & -30,5 & -28,5 \\ & \downarrow & \downarrow & \downarrow & \downarrow \\ 10 & -11,5 & -21,5 & -28,0 & -27,5 \\ 10 & -10,5 & -21,0 & -27,5 & -28,0 \\ 10 & -10,5 & -19,5 & -27,5 & -28,0 \\ & & & & \\ & {\left[\mathrm{~mm}^{3}\right]} & {\left[\mathrm{mm}^{3}\right]} & {\left[\mathrm{mm}^{3}\right]} & {\left[\mathrm{mm}^{3}\right]} \\ & -190,5 & -194,0 & -193,7 & -194,2 \\ x_{\mathrm{O}_{2}} \text { ohne } & \downarrow & \downarrow & \downarrow & \downarrow \\ \text { Zucker } & \downarrow & -127,7 & -180,6 & -194,2 \\ x_{\mathrm{O}_{2}} \text { mit } & -65,1 & -127,6 & \\ \text { Zucker } & & & & \end{array}$

Atmungs.

hem-

$\begin{array}{llll}\text { mung: } & 65,9 \% & 34,2 \% & 6,7 \%\end{array}$

Am Ende der Manometrie werden jedem Gefäß $2 \mathrm{~cm}^{3}$ Zellsuspension entnommen, mit eiskalter Trichloressigsäure enteiweißt, $30 \mathrm{~min}$ bei $0{ }^{\circ} \mathrm{C}$ extrahiert und die Úberstände nach dem Abzentrifugieren der Niederschläge auf Phosphat analysiert. 
Gefäß Nr.

28

$$
29
$$

30

$\mu$ Mole Orthophosphat pro Gefäß

$0,288 \quad 0,769 \quad 1,587$

Ergebnis: Die Erhöhung der 2-Desoxyglucose-Konzentration verursacht steigende Orthophosphatbindung in den Zellen und steigende Atmungshemmung. Interessant ist, daß, abweichend zu den Kulturhefezellen, zunächst eine erhebliche Menge intracelluläres Orthophosphat gebunden werden kann, bis es zur Erniedrigung der Atmung kommt. Ist die Orthophosphat-Konzentration erst soweit erniedrigt, daß Atmungshemmung beginnt, dann führen schon kleine Änderungen der Orthophosphorsäure der Zelle zu relativ großen Änderungen der Atmung.

\section{Protokoll 6}

Die Messung von Atmung und Glykolyse von AscitesKrebszellen in Ascites-Serum mit der Eingefäßmethode. Die Atmungshemmung durch Glucose und 2-Desoxyglucose

Manometrische Bedingungen: $t=38{ }^{\circ} \mathrm{C}, v=220 / \mathrm{min}$, $\varepsilon=10 \mathrm{~mm}$. Kegelförmige Anhängergefäße, die im Anhänger $3 \mathrm{~cm}^{3} 3-m$. $\mathrm{KHCO}_{3}-\mathrm{K}_{2} \mathrm{CO}_{3}(80 / 20 \mathrm{Vol}$.) mit $2 \mathrm{mg}$ "Cartase" enthalten. In den Gasraum werden $5 \mathrm{~min}$ im Stehen $5 \mathrm{Vol} . \% \mathrm{CO}_{2}$-Luft eingeleitet. Als Retentionen für je $3 \mathrm{~cm}^{3}$ Ascites-Serum bzw. Carbonatgemisch wurden folgende Werte bestimmt:

$R_{\mathrm{CO}_{2}}^{\mathrm{Serum}}=0,191 \mathrm{~mm}^{3} \mathrm{CO}_{2} / \mathrm{mm}$ Brodie;

$R_{\mathrm{M}}^{\text {Serum }}=0,46 \mathrm{~mm}^{3} \mathrm{CO}_{2} / \mathrm{mm}$ Brodie;

$R_{\mathrm{CO}_{2}}^{\mathrm{Gemisch}}=69,4 \mathrm{~mm}^{3} \mathrm{CO}_{2} / \mathrm{mm}$ Brodie.

\section{9}

$3,260 \mathrm{~mm}^{2}$

$0,1 \mathrm{~cm}^{3}$ Ascites-

Serum mit 6,2 mg

Glucose

$$
\begin{array}{rl} 
& \Delta h[\mathrm{~mm}] \\
-20,5 & \\
-20,5 & x_{\mathrm{O}_{2}}= \\
-20,5 & -269 \mathrm{~mm}^{3} \mathrm{O}_{2} \\
-20,5 & \\
\downarrow & \\
-7,5 & \\
-7,5 & x_{\mathrm{O}_{2}}= \\
-7,0 & h+h_{\mathrm{M}} \cdot K_{\mathrm{O}_{2}} \\
-7,5 & =-(44,5+4,4) \cdot K_{\mathrm{O}_{2}} \\
-7,5 & x_{\mathrm{O}_{2}}= \\
-7,5 & -158,5 \mathrm{~mm}^{3} \mathrm{O}_{2}
\end{array}
$$

\begin{tabular}{|c|c|c|c|c|c|c|}
\hline \multirow{2}{*}{$\begin{array}{l}\text { Ver- } \\
\text { such } \\
\text { Nr. }\end{array}$} & \multicolumn{3}{|c|}{ mit 2-Desoxyglucose } & \multicolumn{3}{|c|}{ mit Glucose } \\
\hline & $\begin{array}{c}Q_{\mathrm{O}_{2}} \\
\text { ohne } \\
\text { Zucker }\end{array}$ & $\begin{array}{c}Q_{\mathrm{O}_{2}} \\
\text { mit } \\
\text { Zucker }\end{array}$ & $\begin{array}{c}\text { Hem- } \\
\text { mung } \\
{[\%]}\end{array}$ & $\begin{array}{c}Q_{\mathrm{O}_{2}} \\
\text { ohne } \\
\text { Zucker }\end{array}$ & $\begin{array}{c}Q_{\mathrm{O}_{2}} \\
\text { mit } \\
\text { Zucker }\end{array}$ & $\begin{array}{c}\text { Hem- } \\
\text { mung } \\
{[\%]}\end{array}$ \\
\hline $\begin{array}{l}1 \\
2 \\
3 \\
4 \\
5\end{array}$ & $\begin{array}{r}-10,1 \\
-10,9 \\
-12,3 \\
-11,9 \\
-\quad 9,8\end{array}$ & $\begin{array}{l}-4,0 \\
-4,0 \\
-5,0 \\
-4,3 \\
-3,6\end{array}$ & $\begin{array}{l}60,4 \\
63,3 \\
59,4 \\
63,9 \\
63,3\end{array}$ & $\begin{array}{l}-10,2 \\
-11,0 \\
-12,3 \\
-11,9 \\
-10,0\end{array}$ & $\begin{array}{l}-4,9 \\
-6,0 \\
-7,1 \\
-6,9 \\
-5,6\end{array}$ & $\begin{array}{l}53,0 \\
45,5 \\
42,3 \\
42,0 \\
44,0\end{array}$ \\
\hline $\operatorname{im}_{\text {Mittel }}$ & $-11,0$ & $-4,2$ & 61,8 & $-11,1$ & $-6,1$ & 45,0 \\
\hline
\end{tabular}

Tab. 2. Die Hemmung der Atmung von Ascites-Krebszellen durch Glucose und 2-Desoxyglucose. Die Versuchsanordnung ist die des Protokolls 6. Man sieht, daß sich die Atmungshemmungen mit diesen beiden Zuckern deutlich unterscheiden.
In Gefäß 29 wurden in 60 min mit Glucose 16,55 $\mu$ Mole $=370,8 \mathrm{~mm}^{3}$ Milchsäure gebildet. Das entspricht einer Milchsäurekorrektur an der Atmungsmessung von:

$$
h_{\mathrm{M}}=+4,4 \mathrm{~mm} \text {. }
$$

Gefäß Nr. 28 29

Atmungshemmung:

$62,5 \%$ $60,8 \%$

Ergebnis: Glucose und 2-Desoxyglucose erzeugen bei Ascites-Krebszellen annähernd gleich große Atmungshemmungen. Die Ergebnisse von 5 weiteren Versuchen enthält Tab. 2 .

Fräulein Maria Schrader und Fräulein Liselotte PETERSen möchte ich für ihre Hilfe bei der Durchführung der Experimente dieser Arbeit danken; der D e u t $\mathrm{sch}$ en Forschungsgemeinschaft für die Gewährung einer Sachbeihilfe. 